\title{
Aminosidine plus sodium stibogluconate for the treatment of Indian kala-azar: a randomized dose-finding clinical trial
}

\author{
C. P. Thakur ${ }^{1}$, S. Bhowmick ${ }^{1}$, L. Dolfi ${ }^{2}$ and P. Olliaro ${ }^{1,3}{ }^{1}$ Patna Medical College, Tripolia Social Service Hospital, \\ Patna, Bihar, India; ${ }^{2}$ B. A. Oncology, Pharmacia-Farmitalia Carlo Erba, Milano, Italy; ${ }^{3}$ UNDP/World Bank/World \\ Health Organization Special Programme for Research and Training in Tropical Diseases (TDR), Geneva, Switzerland
}

\section{Abstract}

This randomized, open sequential design trial was set up to assess the efficacy, tolerability and toxicity of $20 \mathrm{~d}$ courses of combined intramuscular aminosidine and sodium stibogluconate at various dosages in patients with newly-diagnosed kala-azar in Bihar, India. Three successive studies of 96 patients each were originally planned with aminosidine administered at 12,6 and $3 \mathrm{mg} / \mathrm{kg} / \mathrm{d}$, respectively. For each aminosidine dosage, patients were randomly assigned to receive sodium stibogluconate at 20,10 or $5 \mathrm{mg} / \mathrm{kg} / \mathrm{d}$ of antimony. Ninety-six patients were enrolled and assigned aminosidine $12 \mathrm{mg} / \mathrm{kg} / \mathrm{d}$ as scheduled. In the subsequent study with aminosidine at $6 \mathrm{mg} / \mathrm{kg} / \mathrm{d}$, the trial was interrupted after 40 patients had entered owing to inadequacy of the treatment. With aminosidine $12 \mathrm{mg} / \mathrm{kg} / \mathrm{d}$ the success rates with sodium stibogluconate at 20,10 and $5 \mathrm{mg} / \mathrm{kg} / \mathrm{d}$ were $88 \%, 71 \%$ and $72 \%$, respectively and did not differ significantly. With aminosidine 6 $\mathrm{mg} / \mathrm{kg} / \mathrm{d}, 69 \%, 50 \%$ and $46 \%$ of patients were cured with the same sodium stibogluconate doses, respecively; again, there was no significant difference between the subgroups. The overall success rate with aminosidine at $12 \mathrm{mg} / \mathrm{kg} / \mathrm{d}(76 \%)$ was significantly higher than that with $6 \mathrm{mg} / \mathrm{kg} / \mathrm{d}(55 \%)$ (odds ratio $=2 \cdot 69$; $95 \%$ confidence interval, $1 \cdot 11-6 \cdot 4)$. Patients improved clinically and the treatments were equally well tolerated. The combination of aminosidine $12 \mathrm{mg} / \mathrm{kg} / \mathrm{d}$ and sodium stibogluconate $20 \mathrm{mg} / \mathrm{kg} / \mathrm{d}$ for $20 \mathrm{~d}$ appears to be an effective and safe replacement in Bihar for sodium stibogluconate alone for $\geqslant 40 \mathrm{~d}$.

Keywords: visceral leishmaniasis, Leishmania donovani, aminosidine plus sodium stibogluconate, treatment, India

\section{Introduction}

Response to treatment with organic pentavalent antimonials, the standard first-line treatment for kala-azar (visceral leishmaniasis), has been decreasing over the years in India (INDIA, 1991; THAKUR, 1993). Several papers have reported prolonging courses and increasing dosages in an attempt to compensate for diminishing activity (PETER, 1981; THAKUR, 1984; THAKUR et al., $1988,1991)$. Now there is hardly any patient with kalaazar in Bihar who needs fewer than $40 \mathrm{~d}$ of sodium stibogluconate at $20 \mathrm{mg} / \mathrm{kg} / \mathrm{d}$. Despite such prolonged treatment, the success rate is at present only slightly above $80 \%$ and it is well below $70 \%$ after 3 weeks of treatment. However, adverse reactions are seen more frequently and costs have increased dramatically (THAKUR et al., 1991; OlLIARO \& BRYCESON, 1993).

It is therefore necessary to increase efficacy and also reduce the total drug intake. A probable solution seemed to be combining sodium stibogluconate with aminosidine, which is available as an injectable formulation (Gabbromycin ${ }^{\circledR}$, Farmitalia Carlo Erba). Aminosidine is an aminoglycosidic aminocyclitol antibiotic belonging to the 2-deoxystreptamine subgroup (ARCAMONE et al., 1975). Identity of the catenulin-neomycin antibiotics, including aminosidine and paromomycin, produced by different Streptomyces species, was first recognized by SCHILliNG \& SCHAFFNER (1961). Although the antileishmanial properties of paromomycin (=aminosidine) were first shown by NEAL in 1968, only recently was the drug used in patients with kala-azar (CHUNGE et al., 1990). As this study indicated that the combination of aminosidine and sodium stibogluconate was superior to either drug alone, we did a pilot study to assess the applicability of those results to Indian kala-azar (THAKUR et al., 1992); a $20 \mathrm{~d}$ course of aminosidine at $12 \mathrm{mg} / \mathrm{kg} / \mathrm{d}$ and sodium stibogluconate at $20 \mathrm{mg} / \mathrm{kg} / \mathrm{d}$ was $82 \%$ effective and was well tolerated. The efficacy of combined regimens of aminosidine and antimony has been further documented in visceral leishmaniasis due to Leishmania donovani and disseminated cutaneous leishmaniasis due to $L$. aethiopica by SEAMAN et al. (1993) and TEKLEMARIAM et al. (1994).

A dose-finding study was therefore set up to confirm these encouraging results and to assess the efficacy and safety of different ratios of aminosidine and sodium stibogluconate.

Address for correspondence: P. Olliaro, TDR, World Health Organization, 1211 Geneva 27, Switzerland.

\section{Methods}

Study design and treatment schedules

This was a randomized, open, sequential-design trial. The protocol received ethical clearance by the Indian Drug Controller and the local Ethical Committee. After giving informed consent, patients were enrolled, admitted to hospital and treated at Tripolia Social Service Hospital, Patna, Bihar, India. The study drugs were aminosidine (Gabbromycin ${ }^{\circledR}$, Farmitalia Carlo Erba, Milano, Italy) and sodium stibogluconate (Stibanate ${ }^{\circledast}$, The Gluconate Ltd, Calcutta, India).

The trial was designed to include 3 successive groups of 96 patients, each receiving aminosidine at $12 \mathrm{mg} / \mathrm{kg} / \mathrm{d}$ (group 1), $6 \mathrm{mg} / \mathrm{kg} / \mathrm{d}$ (group 2), or $3 \mathrm{mg} / \mathrm{kg} / \mathrm{d}$ (group 3), but the last dosage was not used (see below). Within each study, patients were randomly assigned to 3 subgroups receiving $20 \mathrm{mg} / \mathrm{kg} / \mathrm{d}$ (subgroup a), $10 \mathrm{mg} / \mathrm{kg} / \mathrm{d}$ (subgroup $b$ ), or $5 \mathrm{mg} / \mathrm{kg} / \mathrm{d}$ (subgroup $c$ ) of sodium stibogluconate. The efficacy of each treatment schedule was to be assessed on the basis of the response rate $(p)$, defined as the proportion of patients with negative spleen aspirate at the end of therapy (day 21). The treatment was to be considered ineffective if $p \leqslant 0 \cdot 65$. Assuming an $\alpha$ level of 0.05 and a power $(1-\beta)$ of 0.8 to detect $p \geqslant 0.85$, it was calculated that 32 patients were required for each dose combination. The trial was to start with patients assigned to aminosidine at $12 \mathrm{mg} / \mathrm{kg} / \mathrm{d}$ (group l). If a group was successfully treated, a further group of 32 patients was to be enrolled and treated with the same dose of sodium stibogluconate and half the dose of aminosidine (i.e., 6 $\mathrm{mg} / \mathrm{kg} / \mathrm{d}$; group 2). Assignment to the sodium stibogluconate dose within each trial (subgroups $a, b$ or $c$ ) was randomized.

Both drugs were administered intramuscularly at different sites for $20 \mathrm{~d}$. Patients were admitted to hospital the day before treatment and remained in hospital for 20 $\mathrm{d}$ treatment and post-treatment assessment on day 21 . Follow-up visits were scheduled for $90 \mathrm{~d}$ and $180 \mathrm{~d}$ after the end of treatment.

\section{Patients}

Only patients with previously untreated kala-azar, diagnosed by finding amastigotes in splenic aspirate and the presence of typical clinical signs and symptoms of kala-azar were included. All patients came from the same geographical area of India (Vaishali, Samastipur, Musaffarpur and Patna districts). 


\section{Clinical and laboratory examinations}

Clinical and laboratory investigations were carried out before starting treatment (baseline values), on days 7 and 14 during treatment, one day after end of treatment (day 21 ), and during the drug-free follow-up period on days 90 and 180 . The examinations included: (i) splenic aspirate to assess parasite load according to CHULAY \& BRYCESON (1983) and measurement of spleen and liver size (from costal margin along the anterior axillary line); (ii) body weight and body temperature; (iii) white blood cell (WBC) counts and haemoglobin determination; and (iv) other haematological and blood chemistry tests, including liver and renal function tests. Electrocardiography (ECG) and audiometry were scheduled before and after treatment.
Clinical laboratory values were classified as normal or abnormal according to whether they were within or outside the normal ranges. To assess the direction of changes, the paired observations of values classified as described above were analysed at the baseline and on day 21 by using $\chi^{2}$ or Fisher's exact two-tailed test (as appropriate) for each treatment group. A stratified analysis was also conducted within each phase and the Mantel-Haenszel weighted OR and $95 \%$ CI were calculated.

All results were assessed at a significance level of $P=0.05$.

\section{Results}

Aminosidine at $12 \mathrm{mg} / \mathrm{kg} / \mathrm{d}$ (group 1 )

The 3 subgroups did not differ with respect to demo-

Table 1. Baseline characteristics of kala-azar patients treated with aminosidine and sodium stibogluconate

\begin{tabular}{|c|c|c|c|c|c|c|}
\hline \multicolumn{4}{|c|}{ Aminosidine dosage ${ }_{12 \mathrm{mg} / \mathrm{kg} / \mathrm{d}}$} & \multirow{2}{*}{\multicolumn{3}{|c|}{$6 \mathrm{mg} / \mathrm{kg} / \mathrm{d}$}} \\
\hline & Mean & $12 \underset{\mathrm{SD}}{\mathrm{mg} / \mathrm{kg} / \mathrm{d}}$ & Range & & & \\
\hline $\begin{array}{l}\text { Age (years) } \\
\text { Weight }(\mathrm{kg}) \\
\text { Temperature }\left({ }^{\circ} \mathrm{C}\right) \\
\text { Parasite grading } \\
\text { Spleen size }(\mathrm{cm}) \\
\text { Liver size }(\mathrm{cm}) \\
\text { Haemoglobin }(\mathrm{g} / \mathrm{dL}) \\
\text { White blood cells }\left(\times 1000 / \mathrm{mm}^{3}\right)\end{array}$ & $\begin{array}{r}24 \cdot 8 \\
37 \cdot 8 \\
37 \cdot 2 \\
2 \cdot 9 \\
8 \cdot 3 \\
3 \cdot 9 \\
8 \cdot 7 \\
3436 \cdot 6\end{array}$ & $\begin{array}{r}14 \cdot 1 \\
13 \cdot 4 \\
1 \cdot 4 \\
1 \cdot 2 \\
3 \cdot 4 \\
2 \\
2 \cdot 2 \\
1280 \cdot 7\end{array}$ & $\begin{array}{c}5-67 \\
11-72 \\
36 \cdot 5-40 \\
1-5 \\
2-16 \\
0-10 \\
3-12 \cdot 4 \\
1350-8000\end{array}$ & $\begin{array}{r}22 \cdot 5 \\
33 \cdot 2 \\
37 \cdot 8 \\
3 \cdot 2 \\
7 \cdot 7 \\
4 \cdot 1 \\
8 \cdot 7 \\
3758 \cdot 8\end{array}$ & $\begin{array}{r}14 \cdot 9 \\
12 \cdot 2 \\
1.4 \\
1.3 \\
3 \\
1.9 \\
1.9 \\
1355.6\end{array}$ & $\begin{array}{c}6-66 \\
12-56 \\
36 \cdot 7-39 \cdot 4 \\
1-6 \\
2-15 \\
1-8 \\
3 \cdot 8-11 \cdot 6 \\
1050-6800\end{array}$ \\
\hline
\end{tabular}

\section{Efficacy}

Effective treatment was defined as a negative splenic aspirate at the end of therapy (day 21). Upon discharge, patients were advised to report for follow-up on days 90 and 180 to monitor the occurrence of relapses and late cures. However, only a descriptive analysis was possible at follow-up due to the low numbers of patients reporting. graphic or baseline characteristics (Table 1).

Test of cure. Treatment la gave the highest proportion of patients with negative splenic aspirate at the end of therapy, though the result was not statistically significantly superior to those obtained in the other groups (Table 2). The proportion of patients with a negative splenic aspirate increased with the length of treatment with all 3 regimens (Table 2).

Table 2. Success rates (conversion from positive to negative splenic aspirate) for kala-azar patients treated with aminosidine and sodium stibogluconate

\begin{tabular}{|c|c|c|c|c|}
\hline & Subgroup $a^{\mathrm{a}}$ & $\begin{array}{l}\text { No. of negative } \\
\text { Subgroup } b^{\mathrm{a}}\end{array}$ & $\begin{array}{l}\text { ts/no. examined } \\
\text { Subgroup } c^{\mathrm{a}}\end{array}$ & Total \\
\hline \multicolumn{5}{|c|}{$\begin{array}{l}\text { Aminosidine dosage } \\
12 \mathrm{mg} / \mathrm{kg} / \mathrm{d} \text { (group 1) }\end{array}$} \\
\hline Baseline & $0 / 32$ & $0 / 32$ & $0 / 32$ & $0 / 96$ \\
\hline Day 7 & $6 / 32(19 \%)$ & $10 / 32(31 \%)$ & $6 / 32(19 \%)$ & $22 / 96(23 \%)$ \\
\hline Day 14 & $18 / 32(56 \%)$ & $17 / 32(53 \%)$ & $17 / 32(53 \%)$ & $52 / 96(54 \%)$ \\
\hline Day 21 & $28 / 32(88 \%)$ & $22 / 31(71 \%)$ & $23 / 32(72 \%)$ & $73 / 95(76 \%)$ \\
\hline \multicolumn{5}{|c|}{$6 \mathrm{mg} / \mathrm{kg} / \mathrm{d}$ (group 2) } \\
\hline Baseline & $0 / 13$ & $0 / 13$ & $0 / 14$ & $0 / 40$ \\
\hline Day 7 & $1 / 13(8 \%)$ & $2 / 13(15 \%)$ & $1 / 13(8 \%)$ & $4 / 39(10 \%)$ \\
\hline Day 14 & $3 / 10(30 \%)$ & $4 / 11(36 \%)$ & $3 / 13(23 \%)$ & $10 / 34(29 \%)$ \\
\hline Day 21 & $9 / 13(69 \%)$ & $6 / 12(50 \%)$ & $6 / 13(46 \%)$ & $21 / 38(55 \%)$ \\
\hline
\end{tabular}

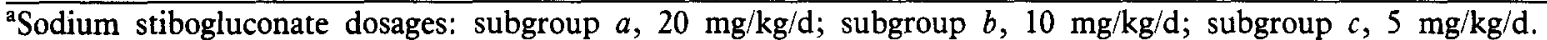

\section{Data handling and analyses}

Data were recorded on individual case record forms, entered into a Lotus $^{\circledR} 123$ computer package, verified and checked, and then transferred to Epilnfo for analysis.

The proportions of patients with negative spleen aspirates were compared within and between each group by calculating $\chi^{2}$; odds ratios (OR) and $95 \%$ confidence intervals $(95 \% \mathrm{CI})$ were also calculated. The distribution of 'cures' by visit was assessed and the results compared with the aid of the Mantel-Haenszel test. A stratified analysis was conducted to compare the success rates in the 2 aminosidine groups and OR and $95 \% \mathrm{CI}$ were calculated.

Paired observations of spleen and liver size and haematological and blood chemistry data were compared at the baseline and on day 21 using the Kruskall-Wallis $H$ test.
Parasite load decreased in all patients but one in group $1 b$; no significant difference was apparent between the subgroups.

Overall, $47(49 \%)$ and $26(27 \%)$ patients reported for follow-up visits on days 90 and 180 , respectively. Of these, 38 and 21 had been classified as treatment successes on day 21 . A relapse occurred in 2 patients in group la (one on day 90 and one on day 180), one in group $1 b$ on day 90 (who became negative again on day 180 ); and 2 in group $1 c$ (one on day 90 and one on day 180).

Conversely, of the 48 patients who reported for at least one follow-up visit, 9 who had been 'failures' at the end of therapy subsequently provided a negative spleen aspirate: 2 each in groups $1 a$ and $1 c$, and 4 in group $1 b$.

Clinical assessment. Most patients improved clinically on treatment. Considering all patients, paired observations showed a significant decrease in spleen size from 
$8.3 \mathrm{~cm}$ (standard deviation [SD] 3.4 ) to $4 \mathrm{~cm}$ (SD 3) $(P<0.001)$ and a substantial, though non-statistically significant, decrease in liver size (from $3.9 \mathrm{~cm}$ (SD 2) to 0.5 $\mathrm{cm}$ (SD 1)).

All patients had a palpable spleen before starting treatment; in 11 of them, the spleen was no longer palpable by the end of treatment, with no difference between groups. Comparing paired measurements of spleen size at baseline and on day 21 , a statistically significant reduction was observed in treatment groups la $(P=0.03)$ and $1 b(P=0.02)$, but not in group $1 c(P=0 \cdot 1)$. However, no statistically significant difference in spleen size reduction was observed between the groups.

Similar findings were obtained with liver size. No statistically significant difference was found in or between the groups when comparing baseline and day 21 . At baseline, 6 patients, 3 in group $1 a, 2$ in group $1 b$ and one in group $1 c$, had a non-palpable liver. On day 21 , the liver was not palpable in 24, 27 and 21 paticnts, respcctively.

Most patients were afebrile by the end of therapy. All had intermittent fever before starting treatment, although a proportion of them had no fever at baseline.

Clinical laboratory results. Overall, WBC counts increased from a mean of $3436.6 \times 10^{3} / \mathrm{mm}^{3}$ (SD $1280.7 \times$ $10^{3}$, range $1340 \times 10^{3}-8000 \times 10^{3}$ ) at the baseline to $4810.6 \times 10^{3} / \mathrm{mm}^{3}$ (SD $1678.37 \times 10^{3}$, range $2000 \times 10^{3}$ $10400 \times 10^{3}$ ) at the end of therapy. No statistically significant difference was apparent among the groups when paired observations before and after treatment were compared for each patient. However, there were significantly more patients with WBC counts within the normal limits after treatment than at the baseline $(\mathrm{OR}=15.52 ; 95 \% \mathrm{CI}$ $32 \cdot 14-60 \cdot 09$ ). Almost all patients had low haemoglobin values at baseline and they remained low after therapy. Total protein increased significantly on treatment from $8.9 \mathrm{~g} / \mathrm{dL}$ (SD 1.7) at baseline to $9.2 \mathrm{~g} / \mathrm{dL}$ (SD 1.5) at the end of therapy. However, most patients had normal pretreatment values.

Tolerability. All 3 regimens were equally well tolerated, and with no patient was treatment discontinued due to an adverse event.

Of the 96 patients treated, $11(11 \%)$ experienced 15 adverse events. Four patients $(13 \%)$ in group la reported 5 adverse events: 3 affected the gastrointestinal system (abdominal pain, nausea and gastrointestinal haemorrhage), one the nervous system (giddiness), and one was a breast abscess. Two patients $(6 \%)$ in group $1 b$ reported 3 adverse events: one abdominal pain, one gastroenteritis and one case of fever. Five patients $(16 \%)$ in group $1 c$ reported 7 adverse events: 3 cases of abdominal pain, one of vomiting, 2 cases of hearing disturbance and one case of herpes infection. One patient in groups $1 a$ and $1 b$ and 2 patients in group $1 c$ reported 2 adverse events each. Only one adverse event was reportedly severe but not drug-related; this occurred in group $1 a$.

No renal toxicity was apparent. At the haseline, most patients had creatinine and blood urea nitrogen (BUN) values falling within the normal limits; post-treatment values of creatinine and BUN remained unchanged from the pre-treatment values. The mean creatinine level was $1.02 \mathrm{mg} / \mathrm{dL}$ (SD 0.57) at the baseline and 0.79 (SD 0.36) after treatment; the corresponding values for BUN were $10.07 \mathrm{mg} / \mathrm{dL}$ (SD 4.56) and $10.1 \mathrm{mg} / \mathrm{dL}$ (SD 3.83).

A significant increase in serum levels was observed for liver enzymes (alanine and aspartate aminotransferases, ALT and AST) in the paired observations. Also, significantly more abnormal values were observed on day 21 than at the baseline. The ORs for increased values after treatment were $3.69(95 \%$ CI $1.35-10.05)$ for ALT and $4.65(95 \%$ CI $1.87-11.55)$ for AST.

No abnormality in the ECG and no change in hearing was found after treatment, although audiometry was performed in only about $10 \%$ of the subjects.

Patient enrolment was stopped after 40 patients had entered the study, owing to inadequacy of the treatment. The patient's baseline characteristics (Table 1) did not differ significantly between the subgroups.

Test of cure. The success rate at the end of therapy was marginally better in group $2 a$ than in groups $2 b$ and $2 c$ (Table 2).

Twenty-four and 12 patients were followed up for 90 and $180 \mathrm{~d}$, respectively; 13 and 7 were classified as treatment success at the end of therapy. A relapse occurred on day 90 in one patient in group $2 c$ and one in group $2 a$, and on day 180 for one patient in group $2 a$ and one in group $2 b$.

Of the 24 patients with at least one follow-up visit, 5 treatment failures on day $21(2,4$ and one in groups $2 a$, $2 b$ and $2 c$, respectively) had negative spleen aspirates after completion of their treatment.

Clinical laboratory results. WBC counts and haemoglobin levels increased, though not significantly, during treatment: mean WBC counts were 3758.75 cells $/ \mathrm{mm}^{3}$ (SD 1256.6) at the baseline and 4384.2 (SD 1684.15) at the end of therapy; haemoglobin values were $8.68 \mathrm{~g} / \mathrm{dL}$ (SD $1 \cdot 86$ ) at the baseline and $10 \cdot 2 \mathrm{~g} / \mathrm{dL}$ (SD 1.64) on day 21 . No difference was apparent between the treatment subgroups.

Tolerability. Four adverse events occurred, 2 in group $1 a$ and 2 in group $1 c$. No statistically significant difference was detected between the paired observations at the baseline and after treatment for all variables tested.

\section{Between-study comparison (aminosidine $12 \mathrm{mg} / \mathrm{kg} / \mathrm{d}$ versus 6 $m g / k g / d)$}

Patients assigned to receive aminosidine at $6 \mathrm{mg} / \mathrm{kg} / \mathrm{d}$ were similar to those enrolled in the $12 \mathrm{mg} / \mathrm{kg} / \mathrm{d}$ study (Table 1).

The overall cure rate at end of therapy was $76 \%$ (73/95) with aminosidine at $12 \mathrm{mg} / \mathrm{kg} / \mathrm{d}$, while it was $55 \%$ $(21 / 38$ ) with aminosidine at $6 \mathrm{mg} / \mathrm{kg} / \mathrm{d}$ (Table 2). The difference in cure rates was statistically significant $\left(\chi^{2}\right.$ test, $P=0.014$ ). Overall, patients receiving aminosidine at 12 $\mathrm{mg} / \mathrm{kg} / \mathrm{d}$ had a $2.69(95 \% \mathrm{CI} 1 \cdot 1-6.4)$ better chance of having a negative splenic aspirate at the end of therapy than did those treated with $6 \mathrm{mg} / \mathrm{kg} / \mathrm{d}$. Similarly, at the end of therapy, stratified analysis of the numbers with negative aspirates among those receiving aminosidine at $12 \mathrm{mg} / \mathrm{kg} / \mathrm{d}$ compared with the numbers among those receiving $6 \mathrm{mg} / \mathrm{kg} / \mathrm{d}$ gave an $\mathrm{OR}=2 \cdot 81(95 \% \mathrm{CI} 1 \cdot 15-6 \cdot 91)$ $(P=0.022)$.

By contrast, comparison of distribution of negative aspirates at successive examinations in the group receiving aminosidine at $12 \mathrm{mg} / \mathrm{kg} / \mathrm{d}$ with that among those receiving $6 \mathrm{mg} / \mathrm{kg} / \mathrm{d}$ showed substantial, though non-significant, differences. The relevant ORs were $3.07(95 \% \mathrm{CI}$ $0.95-10.47)$ with sodium stibogluconate at $20 \mathrm{mg} / \mathrm{kg} / \mathrm{d}$, $2.17(95 \%$ CI $0.71-6.89)$ with sodium stibogluconate at $10 \mathrm{mg} / \mathrm{kg} / \mathrm{d}$, and $2.8(95 \% \mathrm{CI} 0.9-9.02)$ with sodium stibogluconate at $5 \mathrm{mg} / \mathrm{kg} / \mathrm{d}$.

No difference was observed in the incidence of adverse events in patients receiving the 2 aminosidine dosages, nor was any dose-related toxicity apparent with cither drug. Treatment was generally acceptable in spite of the quite large volumes injected intramuscularly.

\section{Discussion}

The aim of this trial was to assess whether a combination of aminosidine and antimony for a shorter duration could substitute for conventional, prolonged antimony and if so what were the limits of the combination in terms of efficacy and safety. The trial was therefore designed to identify effective and safe drug regimens and the sample size was calculated so as to enable identification of major differences among treatments.

Aminosidine alone is active in vitro on $L$. donovani, with no cross-resistance with antimonial drugs: the two drugs act synergistically (S. Croft, personal communication). However, aminosidine and sodium stibogluconate were only additive when tested in vivo in a mouse model 
(MCCOY \& NFAL, 1989). The antileishmanial action of aminosidine is thought to be related to misreading of messenger ribonucleic acid (EDLIND, 1991); the target of pentavalent antimonials is also not known precisely, although various mechanisms have been suggested (BERMAN, 1988). At present, there is therefore no clear explanation for the synergistic action of these drugs in vitro. The slightly dissimilar results obtained in the experiments in vivo (MCCOY \& NEAL, 1989), and partly confirmed by our study, were probably due to the different pharmacokinetic profiles of the 2 drugs.

Combined with antimony, aminosidine at $12 \mathrm{mg} / \mathrm{kg} / \mathrm{d}$ was significantly more effective than at $6 \mathrm{mg} / \mathrm{kg} / \mathrm{d}$. By contrast, no difference was apparent between the various doses of sodium stibogluconate. When combined with aminosidine at either dose, some efficacy was seen even with $5 \mathrm{mg} / \mathrm{kg} / \mathrm{d}$ of sodium stibogluconate for $20 \mathrm{~d}$, a dose regimen that would be devoid of efficacy if given alone. When planning the experiment, we had decided to reject any dosage which was not $65 \%$ or more effective. Although aminosidine at $6 \mathrm{mg} / \mathrm{kg} / \mathrm{d}$ + sodium stibogluconate at all doses used proved effective in $69 \%$ of cases, it was thought to be ethically necessary to close the study of this halved dose of aminisodine as the patients were clearly being offered less efficacious therapy.

The aminosidine $12 \mathrm{mg} / \mathrm{kg} / \mathrm{d}$ + sodium stibogluconate $20 \mathrm{mg} / \mathrm{kg} / \mathrm{d}$ regimen is preferred because, despite not achieving statistical significance, the results indicated that it was more active and no less safe than the other regimens. There was no obvious difference between the groups with respect to the other indicators of efficacy which we evaluated.

Combination therapy with aminosidine has been tested clinically in 2 studies in Africa (CHUNGE et al., 1990; SEAMAN et al., 1993) and in our pilot study in India (THAKUR et al., 1992). In both the Kenya and Sudan trials aminosidine was administered at $15 \mathrm{mg} / \mathrm{kg} / \mathrm{d}$ in conjunction with sodium stibugluconate at $20 \mathrm{mg} / \mathrm{kg} / \mathrm{d}$ for 14 and $15-17 \mathrm{~d}$, respectively. The cure rates at the end of therapy were $100 \%$ and $95 \%$, respectively. A drug-free follow-up was performed in Kenya, assessing the definite cure rate at $87 \%$. In both studies, the combination therapy was significantly more effective than sodium stibogluconate alone.

In Bihar, the cure rate at the end of therapy was $82 \%$ in the pilot study, and $88 \%$ both at the end of therapy and at follow-up with the maximum dose tested, aminosidine $12 \mathrm{mg} / \mathrm{kg} / \mathrm{d}$ and sodium stibogluconate $20 \mathrm{mg} / \mathrm{kg} / \mathrm{d}$ for $20 \mathrm{~d}$, in the current study. These results were remarkably consistent and similar to those obtained in Kenya with 2 weeks' treatment including aminosidine at $15 \mathrm{mg} / \mathrm{kg} / \mathrm{d}$. However, the cure rate in Bihar after 2 weeks of therapy was only $56 \%$ at best. It seems, therefore, that treatment for $14-17 \mathrm{~d}$ with $15 \mathrm{mg} / \mathrm{kg} / \mathrm{d}$ of aminosidine combined with $20 \mathrm{mg} / \mathrm{kg} / \mathrm{d}$ of sodium stibogluconate is highly effective in African kala-azar but would be less likely to succeed in India.

The combination of $14 \mathrm{mg} / \mathrm{kg} / \mathrm{d}$ aminosidine with sodium stibogluconate $10 \mathrm{mg} / \mathrm{kg} / \mathrm{d}$ has also proved effective and safe in a limited number of patients with diffuse cutaneous leishmaniasis caused by $L$. aethiopica (see TEKLEMARIAM et al., 1994).

Treatments were well tolerated and no dose-related toxicity was apparent. Only liver enzymes rose slightly on treatment, which is a probable sign of antimony toxicity. However, these $20 \mathrm{~d}$ courses with sodium stibogluconate did not result in any cardiac toxicity, which highlights an additional benefit of combining antimony and aminosidine and curtailing therapy. It is unfortunate that, for technical reasons, post-treatment audiograms could be performed on only a limited number of patients; the available data do not suggest ototoxicity.

The principal flaw of this study might be seen in the drug-free follow-up. Despite contacting patients, travelling and general inconvenience prevented many from reporting for the scheduled assessments. The late 'cures' and relapses observed indicate the need for more stringent planning of follow-up visits in future studies, including provision of financial support for travelling and lost income. However, even with all the weaknesses of follow-up in the present study, the overall conclusions did not differ after including the available information on relapses and late successes.

Based on our results and those reported elsewhere, we therefore conclude that at least $12 \mathrm{mg} / \mathrm{kg}$ of aminosidine should be given daily for $20 \mathrm{~d}$ when combined with the standard dose of sodium stibogluconate for the treatment of Indian kala-azar. Under the conditions of our study this regimen appears to be highly effective and well tolerated.

Further studies supported by the UNDP/World Bank/WHO Special Programme for Research and Training in Tropical Diseases are being conducted in order to assess the efficacy and safety of aminosidine alone. Another study is being planned to compare the combined treatment with standard antimonial therapy in the same patient population.

\section{Acknowledgements}

We are grateful to Professor L. Donno for his invaluable help in designing and setting up this study and to Ms A. Maniero, Professor C. Praga, Dr S. Gothokar and Mr U. Khaul (Farmitalia Carlo Erba) for assistance in the preparation and follow up of the study. We also thank Sister Clementina, Tripolia Social Service Hospital, for her good care of the patients. The contribution of Dr A. Bryceson (Hospital for Tropical Diseases, London, UK) to the aminosidine programme is also warmly acknowledged. We are indebted to Mrs L. Baldry and Dr F. Neva (NIH) for reviewing the manuscript.

This study was supported by a grant from Farmitalia Carlo Erba, Milano, Italy. At the time the study was set up, P. Olliaro was employed as a scientist at $R$ \& D Anti-infectives, Farmitalia Carlo Erba, Milano, Italy (now Pharmacia-Farmitalia Carlo Erba).

\section{References}

Arcamone, F., Bertazzoli, C., Buogo, A., Cassinelli, G. \& Vigevani, A. (1975). New studies in the field of aminoglycosidic aminocyclitol antibiotics. Panminerva Medica, 16, 9-24.

Berman, J. D. (1988). Chemotherapy for leishmaniasis: biochemical mechanisms, clinical efficacy, and future strategies. Reviews of Infectious Diseases, 10, 560-586.

Chulay, J. D. \& Bryceson, A. D. M. (1983). Quantitation of amastigotes of Leishmania donovani in smears of splenic aspirates from patients with visceral leishmaniasis. American fournal of Tropical Medicine and Hygiene, 32, 475-479.

Chunge, C. N., Owate, J., Pamba, H. O. \& Donno, L. (1990). Treatment of visceral leishmaniasis in Kenya by aminosidine alone or combined with sodium stibogluconate. Transactions of the Royal Society of Tropical Medicine and Hygiene, 84, 221225.

Edlind, T. D. (1991). Protein synthesis as a target for antiprotozoal drugs. In: Biochemical Protozoology, Coombs, G. H. \& North, M. J. (editors). London \& Washington, DC: Taylor \& Francis, pp. 569-586.

India (1991). Report of the Expert Committee on Kala-Azar in Bihar. North Delhi: Directorate general of Health Services, Ministry of Health and Family Welfare, Government of India.

McCoy, N. G. \& Neal, R. A. (1989). The effect of combinations of sodium stibogluconate with other antileishmanial agents against Leishmania donovani. Transactions of the Royal Society of Tropical Medicine and Hygiene, 83, 428.

Neal, R. A. (1968). The effect of antibiotics of the neomycin group on experimental cutaneous leishmaniasis. Annals of Tropical Medicine and Parasitology, 62, 54-62.

Olliaro, P. L. \& Bryceson, A. D. M. (1993). Practical progress and new drugs for changing patterns of leishmaniasis. Parasitology Today, 9, 323-328.

Pctcr, W. (1981). The treatment of kala-azar: new approaches to an old problem. Indian Fournal of Medical Research, 73, supplement, $1-18$.

Schilling, R. T. \& Schaffner, C. P. (1961). Differentiation of catenulin-neomycin antibiotics: identity of catenulin, paromomycin, hydroxymycin and aminosidine. Antimicrobial Agents and Chemotherapy, 4, 274-285.

Seaman, J., Pryce, D., Sondorp, H. E., Moody, A., Bryceson, A. D. \& Davidson, R. N. (1993). Epidemic visceral leishma- 
niasis in Sudan: a randomized trial of aminosidine plus sodium stibogluconate versus sodium stibogluconate alone. 7oumal of Infectious Diseases, 168, 715-720.

Teklemariam, S., Hiwot, A. G., Frommel, D., Miko, T. L., Ganlov, G. \& Bryceson, A. (1994). Aminosidine and its combination with sodium stibogluconate in the treatment of diffuse cutaneous leishmaniasis caused by Leishmania aethiopica. Transactions of the Royal Society of Tropical Medicine and Hygiene, 88, 334-339.

Thakur, C. P. (1984). Epidemiological, clinical and therapeutic features of Bihar kala-azar (including post kala-azar dermal leishmaniasis). Transactions of the Royal Society of Tropical Medicine and Hygiene, 78, 391-398.

Thakur, C. P. (1993). Diminishing effectiveness of currently used drugs in kala-azar and on the effect of amphotericin B in antimony and pentamidine resistant kala-azar. In: Current Trends in Leishmania Research, Blanduri, A. N., Basu, $M$. K., Sen, A. K. \& Kumar, S. (editors). New Delhi: Council of Scientific and Industrial Research.
Thakur, C. P., Kumar, M., Kumar, P., Mishra, B. N. \& Pandey, A. K. (1988). Rationalization of regimens of treatment of kala-azar with sodium stibogluconate in India: a randomized study. British Medical fournal, 296, 1557-1561.

Thakur, C. P., Kumar, R. \& Pandey, A. K. (1991). Evaluation of efficacy of longer duration of therapy of fresh cases of kalaazar with sodium stibogluconate. Indian Foumal of Medical Research, 93, 103-110.

Thakur, C. P., Olliaro, P., Gothoskar, S., Choudhury, B. K., Prasad, S., Kumar, M. \& Verma, B. B. (1992). Treatment of visceral leishmaniasis (kala-azar) with aminosidine (= paromomycin)-antimonial compounds, a pilot study in Bihar, India. Transactions of the Royal Society of Tropical Medicine and Hygiene, 86, 615-616.

Received 20 fuly 1994; revised 13 September 1994; accepted for publication 21 September 1994

\section{Announcements}

\section{The Basics of Travellers' Health \\ Swiss Tropical Institute Basel and the International Society for Tropical Medicine}

This short certificate course will be held in Basel from 26-29 June 1995. It is intended to prepare professionals (doctors, senior nursing staff, educators, teachers, trainers and travel industry staff) to give advice to travellers and on the treatment of travel-related diseases, with the main emphasis on the tropics.

The course will be taught in English and the fee is Swiss francs 550.-

Applications must be received by 31 May 1995 . Further information can be obtained from Mrs M. Slaoui, Swiss Tropical Institute, Socinstrasse 57, P.O. Box, CH-4002 Basel, Switzerland; phone +41 612848280 , fax +44612717951 , telex 962508 .

\section{Gender, Health and Technology}

Entries are required for the fifth IDRC/TDR award on gender and tropical diseases. The award (Canadian $\$ 5000$ ) will be given to the author or authors of the best paper on this subject. Ideally, the papers should focus on one or more of the TDR's target discases; they must be original and not previously published, but may be based either on secondary sources or original research. Previous winners of an IDRC/TDR award are not eligible.

Papers must be written in English, French or Spanish and must have a brief summary in English; they should not exceed 30 typed, double-spaced A4 pages and must be submitted by 30 April 1996. It would be helpful if intending authors informed Dr Carol Vlassoff (address below) well in advance of the deadline.

Papers should be submitted to Dr Carol Vlassoff, Manager, Gender and Tropical Diseases Task Force, TDR/WHO, 1211 Geneva 27, Switzerland. 